\title{
WestVirginiaUniversity
}

THE RESEARCH REPOSITORY @ WVU

Graduate Theses, Dissertations, and Problem Reports

2016

\section{Effects of executive functioning on false memory in children}

\author{
Pamela Swift Tessier
}

Follow this and additional works at: https://researchrepository.wvu.edu/etd

\section{Recommended Citation}

Swift Tessier, Pamela, "Effects of executive functioning on false memory in children" (2016). Graduate Theses, Dissertations, and Problem Reports. 7135.

https://researchrepository.wvu.edu/etd/7135

This Dissertation is protected by copyright and/or related rights. It has been brought to you by the The Research Repository @ WVU with permission from the rights-holder(s). You are free to use this Dissertation in any way that is permitted by the copyright and related rights legislation that applies to your use. For other uses you must obtain permission from the rights-holder(s) directly, unless additional rights are indicated by a Creative Commons license in the record and/ or on the work itself. This Dissertation has been accepted for inclusion in WVU Graduate Theses, Dissertations, and Problem Reports collection by an authorized administrator of The Research Repository @ WVU.

For more information, please contact researchrepository@mail.wvu.edu. 
Effects of executive functioning on false memory in children

Pamela Swift (Tessier), M.S.

Dissertation submitted to the Eberly College of Arts and Sciences at West Virginia University in partial fulfillment of the requirements

for the degree of

Doctor of Philosophy

in

Psychology

Elisa Krackow, Ph.D., Chair Cheryl McNeil, Ph.D.

Hawley Montgomery-Downs, Ph.D.

Constance Toffle, Ph.D.

Karen Harper-Dorton, Ph.D.

Marissa Carey, Ph.D.

Department of Psychology

Morgantown, West Virginia 2016

Keywords: false memory, executive functioning, children's memory Copyright 2016 Swift 


\begin{abstract}
Effects of executive functioning on false memory in children

By Pamela Swift (Tessier), M.S.
\end{abstract}

Misremembering is a common phenomenon in normal human development that has great potential to become problematic, especially in legal situations. The Deese/Roediger-McDermott (DRM; Deese, 1959; Roediger \& McDermott, 1995) model has been commonly used in the literature to uncover mechanisms for why these false memories may occur. Children have only recently begun to be investigated using this paradigm. Some related mechanisms in children for false recollection that have yet to be investigated are child executive functioning and socioeconomic status. In the current study, executive functioning was investigated as a potential mechanism for false recollections using a DRM paradigm. Children completed a brief assessment of intelligence followed by assessments of executive functioning. Participants then engaged in the DRM recall and recognition task. Finally, they completed a semantic knowledge task. Results indicated that specific aspects of executive functioning (inhibition and cognitive flexibility) predicted false memory production at both recall and recognition. Additionally, maternal education and gross family income had predictive value at recall and recognition. However, a mediational model was not supported. These results help explain mechanisms for false memory and can provide valuable information regarding susceptibility to false memory production. 
Table of Contents

1. Introduction

a. False Memory

i. Leading question and misinformation 2

ii. Implanted autobiographical memory 4

iii. Deese/ Roediger/ McDermott false memory methodology and related theory 5

iv. DRM in adults 8

v. DRM in children 9

b. Individual Differences in False Memory $\quad 10$

i. Executive functioning and socioeconomic status 13

ii. Semantic knowledge 16

2. Current Study 18

a. Hypotheses and Exploratory Questions 18

3. Methods 20

a. Participants 20

b. Materials 21

c. Procedure 24

4. Results 25

a. Immediate False Memories: Free Recall Memory Accuracy 26

b. Delayed False Memories for the Critical Lure: Recognition 28

c. Hit Rate on Recognition 28

d. False Alarm Rate on Recognition 28

5. Discussion 29

6. References $\quad 35$

7. Table $1 \quad 47$

8. Table $2 \quad 48$

9. Table $3 \quad 49$

10. Table $4 \quad 50$

11. Table 5

12. Figure 1

13. Table 6

14. Table $7 \quad 54$

15. Table 8 
Effects of executive functioning on false memory in children

Misremembering is a common phenomenon throughout the lifespan. People of all ages are prone to false recollection of names, lists, places, and so on (e.g., Metzger et al., 2008; Gold et al., 2007; Sugrue \& Hayne, 2006). Misremembering may not be a terribly detrimental event; falsely remembering that one needs to purchase sugar at the grocery store is not going to have a dramatic impact on a person's life or the life of another. However, false memory becomes far more important when it occurs in a legal context. For instance, in eyewitness memory reports, a false memory has potential to influence court cases in a significant way. Thus, regardless of the usual banality of false memories in everyday life, their considerable impact in legal contexts warrants extensive investigation. And, over and above the false memory itself, more inquiry into the correlates (i.e., the neurocognitive correlates) of their production could result in valuable information that may point further mechanisms for the induction of false memories.

\section{False Memory}

Several theories have been put forth to describe the how false memories occur. Of these, Fuzzy-Trace Theory (Brainerd \& Reyna, 2004; Reyna \& Brainerd, 1995) accounts for the most parsimonious explanation for false memory development. Fuzzy-Trace Theory states that, following an event, people are able to unearth two distinct memory traces; verbatim and gist. The verbatim trace, or the verbatim memory for stimuli, includes specific features of events such as perceptual features. The gist trace is schemabased or contains the overall theme of the presented words. When the verbatim trace fades, the gist trace takes over and false memories are more likely to occur. For example, after being presented with a verbal narrative that did not mention how a college student 
learned of the death of his family dog, one-week later verbatim memory had faded such that numerous participants could no longer recall the narrative word for word (verbatim trace). Gist memory took over and numerous adult participants falsely recalled that he learned the news via receiving a phone call from his parents (raw data from Krackow, Kania, \& Travers, 2013). Fuzzy-Trace Theory is not specific to a single paradigm but applies more generally to memory development and applies to a variety of cognitive processes. Findings consistent with predictions based on Fuzzy-Trace Theory appear in the literature on development of memory (Brainerd, Reyna, \& Howe, 2009), false memories (Holliday, Brainerd \& Reyna, 2010), false confessions (Reyna, Holliday, \& Marche, 2002) and in other domains of cognition such as risky decision making (Reyna et al., 2011) and cognitive functioning in Alzheimer’s disease (Brainerd et al., 2011). The application of Fuzzy-Trace Theory to common procedures used to induce false memories is reviewed below.

\section{Leading Questions and Misinformation}

Elizabeth Loftus, a pioneer in the field of eyewitness memory research, began considering how false memories came about four decades ago (Loftus \& Palmer, 1974). Loftus went on to discover methods for inducing false memories, including the use of leading questioning. Loftus (1975) conducted a series of experiments with nearly 500 undergraduate students at the University of Washington with the premise that simple changes in the wording of a question may induce a false memory. Loftus was one of the first researchers to consider the importance of transitioning memory research from word lists to actual events. Loftus cited her own published and unpublished research which suggested that memories regarding events, whether they be benign (e.g., one's history of 
headaches) or a recently viewed car accident, were highly influenced based on the wording of questions ("about how fast were the cars going when they bumped/hit/smashed into each other?” p. 565). Stronger words (e.g., smashed) elicited responses indicating higher speeds of the cars. If one accepts the leading terms of the question, then that portion is incorporated into their memory. Later on, one may respond to questions based on this construction that has the false memory in tow. In sum, Loftus describes memory process as forming a cognitive representation of an experience followed by a cognitive modification of that experience when additional information is encountered. When this original event is remembered, the newly formed representation is what is recalled as opposed to the original experience. This can lead to erroneous responses if questioned about the original experience. If, during acquisition, a falsity is introduced and accepted, later retrieval will result in the revival of that false memory. Loftus furthered this line of investigation to discover that misinformation can be used in other ways, aside from leading questions, to create false memories. The misinformation paradigm generally includes three steps: experiencing or hearing about an event (presentation stage), receiving information following the event (suggestion stage), and a test of memory (test stage) (Loftus, 2005a; Loftus, 1975). The induction of false memories is robust using this type of paradigm in both adults and children (Bruck \& Ceci, 1999; Ceci, Ross, \& Toglia, 1987). Fuzzy-Trace Theory explains false memories in this paradigm as the original event presented (verbatim trace) diminishes and the suggested post-event information becomes incorporated into the memory trace. After this occurs, the schema-based memory for the event takes over (gist memory) and is recalled. 


\section{Implanted Autobiographical Memory}

Of particular concern in legal cases are implanted, or “repressed/recovered,” autobiographical memories (Loftus, 1993). Memories of this type include recollections for whole events that one believes they have experienced or witnessed. Several studies have considered the situations and conditions where false autobiographical memories can be implanted. The general methodology used across studies is that participants are provided with a cover story of some sort to increase the likelihood that they will believe the false memory induction (i.e., to make it plausible). Memories are implanted using a variety of memory implantation techniques, often techniques used by memory recovery therapists (Lynn, Lock, Loftus, Krackow, \& Lilienfeld, 2003) such as guided imagery, and participants are asked to report these memories aloud. For example, Mazzoni and Memon (2003) provided participants with a bogus cover story about a made up medical procedure that supposedly occurred when the adult participants were young children. The researchers then used imagination to recover memories of this childhood event. Forty percent of participants in the condition produced false memories, which was substantially higher than a control condition. Therefore in these studies and in real world memory recovery cases, autobiographical memories, including memories from childhood, are weak. Recollections that coincide with the gist memory are created via presentation of a cover story that includes some specific details of the event. The person is then left with the feeling that this event may have occurred (it becomes "familiar" according to Brainerd \& Reyna, 2002) and generates specific details consistent with the suggested gist (Brainerd \& Reyna, 2002). In the real world, this process is magnified by numerous sessions in which memory recovery takes place, including expectancies that the client 
will be able to recall the traumatic event (Lynn et al., 2003). The person then comes to believe this false memory.

\section{Deese/ Roediger/ McDermott False Memory Methodology and Related Theory}

The Deese/ Roediger/ McDermott (DRM) methodology has been regularly and reliably used to study the production of false memories (Howe, 2005; Roediger \& McDermott, 1995). This methodology utilizes lists that contain words that can all be categorized under a larger categorical term such as a basic level term (Blewitt \& Krackow, 1992). For example, a list may contain items like Dalmatian, collie, English setter, boxer, but will not include the word “dog.” Despite this larger, categorical term being left off the list, older children (Metzger et al., 2008) and adults (Howe, 2005; Sugrue \& Hayne, 2006) have a consistent, strong tendency to remember that basic-level word. False memory for the "critical lure” is referred to as the DRM effect.

False memories produced by the DRM effect are consistent with the most parsimonious theory of false memory development, Fuzzy-Trace Theory (Brainerd \& Reyna, 2004; Reyna \& Brainerd, 1995). Findings using the DRM model reveal that older children and adults tend to exhibit higher rates of false memories than younger children (Holliday, Brainerd, \& Reyna, 2011). This phenomenon is referred to developmental reversals in false memories (Holliday et al., 2011). Fuzzy-Trace Theory has been used to explain what is deemed the developmental reversal phenomenon; both verbatim and gist memory increase with age, but it is the increase in gist memory that leads to reconstructive memory processes (Holliday et al., 2011).

A second theory provides another explanation specifically for DRM false memories, essentially suggesting that as individual's age, they are more likely to activate 
memory systems that make them more capable of false memory. Association Activation Theory (Howe, 2006) suggests that the critical lure in a DRM paradigm is activated via semantic networks after reading the list items. Words that are more highly associated with the critical lure would thus be more likely to activate semantic networks and lead to false memory. These theories ultimately fit with evidence indicating that young children are less prone to the DRM effect since they activate different memory networks than older children and adults. Howe, Wimmer, and Blease (2009) assessed Association Activation Theory, specifically backward associative strength, using DRM and categorical lists. Backward associative strength refers to the strength between items in the DRM list and the critical lure. They hypothesized that backward associative strength would be key in false memory production. Using DRM lists (e.g., for the critical lure bird-nest, fly, feathers) and category lists (e.g., bluejay, canary, eagle). Participants read lists that were either categorical or DRM and either high, low, or equal in backward associative strength. They discovered that false recall and recognition of these lists increased (regardless of whether they were categorical or DRM) as backward associative strength increased. This corroborated the assumptions of Association Activation Theory.

A third theory for false memories in the DRM methodology was developed by Roediger and McDermott (2000). They explained this in a similar manner to Association Activation Theory and referred to this theory as Activation-Monitoring Theory. They described a similar mechanism by which, upon being presented with the list, individuals activated the critical lure using their semantic networks. Thus, in adults, words with strong associations are activated quickly and consistently, leading to heightened true and false recall. The added component to their theory was a source-monitoring component, 
which theoretically would reduce false memories. By making a decision about the source of the memory, individuals should be better able to discount critical lures that may have been brought to the forefront of their memory by semantic activation. This second aspect of Activation-Monitoring Theory is suspect. Source-monitoring capabilities have been found to increase with age (e.g., Roberts, 2000). Thus, logically children would then be more prone to false memories. Indeed, this finding has been seen on occasion in the literature (see Ghetti, Qin, \& Goodman, 2002). However, the majority of research points to young children having fewer false memory recollections using the DRM paradigm.

Specifically, the DRM methodology can serve as a proxy for real-life event false memories. Reyna and colleagues (2007) argued that DRM word lists work in the same way that memories for repeated exposure to abuse or neglect work. For example, if a child victim of crime experiences similar events over the course of years, recent events may cue memories for earlier events. By connecting these events, the details may become fuzzy and intertwined. Reyna, Holliday, and Marche (2002) reviewed the implications of the dominant theory behind why DRM memories occur (Fuzzy-Trace Theory). They contended that Fuzzy-Trace Theory is incredibly pertinent in forensic investigations, especially when children are being interviewed with leading questions or open-ended free recall. Additionally, Poole (1995) argued that verbatim memories may become “gistified.” Specifically, Poole noted that the predominant theory of DRM can be seen in other contexts aside from those specifically mentioned in Fuzzy-Trace Theory research. Brainerd, Reyna, and Poole, (2000) reasoned in their chapter that DRM and Fuzzy-Trace Theory have their place in legal contexts; if a child is put through a round of leading questions, the gist for an event may be made more apparent in the process, making their 
verbatim trace disappear. This is ultimately the same as the events that occur in the DRM paradigm. The word list elicits the gist and the verbatim trace cannot discount it. Therefore, false memory results from the same processes regardless of whether the memory is for a traumatic event or word lists.

In summary, the preponderance of evidence points to DRM being a valid inductor for false memory in research and proxy for real-life event false memories. This is largely due to Fuzzy-Trace Theory and the broad reach of the theory in memory research. Research using the DRM methodology in adults and children will now be reviewed. Initially, research on the DRM false memories using DRM methodology was conducted primarily with adults. In recent years, children have been included when studying this method of inducing false memories.

\section{DRM in adults}

The literature on the DRM effect has largely focused on adults. Adults, compared to children, are more prone to falsely recalling critical lures when lists are longer (Sugrue \& Hayne, 2006), but also have more accurate recall (Metzger et al., 2008) suggesting a developmental trend; as individuals age, they are not only able to accurately recall words at a better rate, they are also more prone to false recall.

Khanna and Cortese (2009) investigated the importance of presentation modality when using DRM lists. Specifically, they assessed children (ages 8-9) and adults’ false memories when presenting lists orally and visually. Interestingly, the authors found that, with orally presented lists, children had a higher proportion of false to true recall. Adults showed the opposite trend. They also found a relatively higher false recall rate in children. When using visual (written) lists, adults had higher rates of false and true recall 
than children. These results suggested that adults process information differently and in a more consistent manner than children, regardless of modality, since their proportion and relative rates of false memory stayed fairly similar. The authors suggested that when studying false memories, information-processing differences must be considered.

\section{DRM in children}

Relatively recently, researchers have begun to consider how DRM lists may impact the memory of children. In general, younger children have been found to be less prone to the DRM effect (e.g., Howe 2005; Metzger et al., 2008). This may seem counterintuitive, but theories (see above) suggest that this is due to less developed language and memory systems.

Holliday, Reyna, and Brainerd (2008) found a developmental increase in memory of critical lures in children ages 7-to-13-years-old. Specifically, 7-year-olds remembered significantly fewer lures than older children. It seemed that repetition of lists, as well as giving children the theme of the list (different from the critical lure), increased false memories as well. Children as old as fifth-graders have been found to make DRM errors in a similar manner to adults in low-demand (i.e., recognition) scenarios (Metzger et al., 2008). As noted previously, Khanna and Cortese (2009) uncovered that 8- to 9-year-olds are capable of having proportionately and relatively higher rates of false memory than adults. Metzger and colleagues (2008) ran a series of experiments using modified DRM lists with words approved by $2^{\text {nd }}$ grade teachers and piloted on children $\left(2^{\text {nd }}\right.$ and $5^{\text {th }}$ graders). When using these associative word lists, Metzger et al. (2008) noted an advantage; by using developmentally appropriate lists, younger children demonstrated an increase in accurate recall and made fewer recall and recognition errors. College students 
also improved in their false recognition errors when using lists including words approved for younger children.

Children’s remembering capabilities could also be affected by the emotional valence of the word list. Howe, Toth, and Cicchetti (2011) considered this important area of inquiry with both maltreated and non-maltreated child participants (ages 6-12). Memory distortions following trauma are not uncommon (e.g., Cicchetti \& Valentino, 2006) and, should legal proceedings result from trauma, these false or distorted memories could be detrimental in court. As per developmental trend, older children recalled more words and this occurred regardless of maltreatment history. However, children had a harder time suppressing emotional words when told that they should forget the emotional list in favor of remembering a second list. Thus, although still capable, children overall have a more difficult time suppressing emotional words as opposed to neutral words. To summarize, the research suggests that older children and adults are equally susceptible to DRM errors and, thus, are potentially likely to exhibit false memories after list presentation.

\section{Individual Differences in False Memories}

Individual differences are an important area of consideration in regards to how false memories are produced. Aside from age, researchers have identified several factors that may influence false memory induction on an individual basis. For example, individuals who have experienced trauma or sexual abuse in the past (and have notable PTSD symptoms) may be more prone to false memories (Goodman et al., 2011). Zhu and colleagues (2010b), using a misinformation paradigm, discovered several personality dimensions related to false memory, including persistence, cooperativeness, self- 
dependence, reward-directedness, and coping skills. Additionally, depression and cognitive abilities were also (negatively) correlated with false memory production (Zhu et al., 2010b). Finally, studies have considered how socioeconomic status may affect the induction of false memories (Howe, Cicchetti, \& Toth, 2004). There is a wealth of research still to be done on why false memories are more likely to be produced in one person, but not another.

Nearly all of the studies reviewed below have used an undergraduate population and have only begun to scratch the surface of the relationship between neuropsychological functioning and false memories. Bixter and Daniel (2013) explored the relationship between false recollection and working memory using two different experiments; one with a forewarning for participants about the tendency of DRM lists to lead to false memories and another where this forewarning was absent. Those participants with larger working memory capacity had fewer false memories, but also fewer "remember" responses, or responses where the participant consciously recollected the word (as opposed to having a "feeling" that it was a word they had seen before), though this was only when a forewarning regarding the DRM task occurred. Peters and colleagues (2006) also discovered slight executive dysfunction in undergraduate students who tended to falsely remember critical lures. In Howe, Toth, and Cicchetti ‘s (2011) assessment of both maltreated and non-maltreated children's memory abilities, they also considered verbal and perceptual IQ in order to relate cognitive functioning to these inhibitory abilities. They found that children's verbal IQ was significantly associated with their recall rates. When verbal IQ was controlled for, maltreated and non-maltreated children had similar recall abilities. Additionally, older children (ages 10-12) were better 
able to recall true memories than younger children (ages 6-9), but the groups were equal in their false memory recall rates. Zhu and colleagues (2010a) assessed the relationship between cognitive factors (intelligence, perception, memory, and face judgments) and false memories after a misinformation test in college students. The misinformation test included a 50-slide story told in pictures, of which 12 were particularly important since they were to be inaccurately described in a narration following a 30-minute delay. These narrations were 50 sentences, one for each slide, with 12 being inaccurate. Following another 10-minute delay, participants completed two tasks; one related to recognition and another that assessed source monitoring abilities. Their results suggested that lower intelligence and visuospatial skills were linked to increased false recognition memories, but that having false memories is not necessarily indicative of simply poor memory in general. Specifically, having what researchers deemed “Robust False Memory” (e.g., endorsing the pictures as the source of their false memory or saying that the picture and the narration were both the same) was not significantly associated with recall and recognition tasks on the Wechsler Memory Scales. Additionally, when including other cognitive abilities in a regression, memory scores did not uniquely predict false recognition memory, suggesting that other areas of cognition should be considered in this process.

Studies have already suggested that working memory capacity is associated with false memory induction, but no studies have simultaneously assessed other executive function capacities (e.g., cognitive flexibility and inhibition). Tests of inhibition, or the ability to control one's attention in order to ignore or override external lures (Diamond, 2013) may be associated with false memory, especially in the DRM task. Inhibitory 
control may be necessary in order to ignore the gist of the DRM list and only recall the verbatim list. More broadly, being able to discount and override information from past experiences and events is crucial to event reporting as an eyewitness. Additionally, cognitive flexibility, which Diamond (2013) conceptualizes as being built from the other two areas of executive functioning, may be important in false memory. The ability to change focus and perspective is enormously important in legal cases where techniques like the cognitive interview, which includes a change perspectives component, are being used to obtain a narrative of an event from a child. As a result, having enhanced cognitive flexibility makes false memory induction more difficult. Finally, socioeconomic status has been demonstrated as having an effect on both executive functioning and false memory production; specifically, children from lower socioeconomic status backgrounds are more prone to deficits in executive functioning (Carlson \& Meltzoff, 2008; Hackman \& Farah, 2009; Hackman, Farah, \& Meaney, 2010) and more false memories (Howe, Cicchetti, \& Toth, 2006). Thus, socioeconomic status will be an important consideration for the current study.

\section{Executive functioning and socioeconomic status.}

Executive functioning comprises several cognitive skills including planning, working memory, inhibitory control, attention, and cognitive flexibility, among other higher-order skills. Executive functioning has been shown to be moderately correlated with IQ with ranges, depending on the executive functioning test, of $R^{2}$ from .14 to .55 (Arffa, 2007). Recent evidence suggests that socioeconomic status, a proxy for several variables related to family income and access to community resources, may impact neuropsychological functioning (e.g., Noble, Houston, Kan, \& Sowell, 2012; Blair 2010). 
Noble and colleagues (2012) found that differences in socioeconomic status, over and above race, IQ, and gender differences, were highly associated with differences in brain volume across the hippocampus and the amygdala. Differences in the left superior temporal gyrus and left inferior frontal gyrus were also associated with socioeconomic status differences and increased with age. Noble and her colleagues suggested that home linguistic environment and stress may be the mechanisms of these variations. Blair (2010) discussed the effects of early environmental stress resulting from insufficient resources on hormones and neurotransmitters. Blair noted that, for example, heightened presence of cortisol could change neural development, altering executive functioning and behavioral skills. Additionally, Blair and colleagues (2011) found that higher levels of salivary cortisol during infancy and toddlerhood was related to diminished executive functioning abilities at age 3. Noble and colleagues (2012) proposed a model by which socioeconomic status may impact neurocognitive capabilities, including language development, memory, and other aspects of executive functioning. Specifically, they suggest that stress and the linguistic environment at home impacts memory, emotion, and self-control centers, as well as areas of the brain important for language development in the brain (Noble, Houston, Kan, \& Sowell, 2012). Additionally, even exposure to stress in the prenatal environment can have lasting effects in childhood and adolescence in regard to hippocampal volume (Qui et al., 2013), cortical volume (Davis et al., 2013) and amygdala volume (Buss et al., 2012).

The brain areas involved in executive functioning processes (e.g., the prefrontal cortex) do not tend to reach full development until the early 30s (e.g., Watson et al., 2011). Researchers have suggested that this slow postnatal maturation may make 
individuals more susceptible to environmental influences, including the effects of low environmental resources from growing up in a low socioeconomic status family (Hackman \& Farah, 2009; Hackman, Farah, \& Meaney, 2010). Recently, Nesbitt, BakerWard, and Willoughby (2013) examined executive functioning as a mediator in the relationship between socioeconomic status and race on academic achievement. Socioeconomic status and racial identity did not have any direct effect on mathematic or literary achievement outcomes, but worked indirectly through kindergarten executive functioning. Specifically, higher socioeconomic status and being of European (rather than African American) descent was related to higher kindergarten executive functioning, which led to higher math and literary achievement.

Historically, socioeconomic status has been an incredibly difficult construct to measure. The APA Task Force on Socioeconomic Status (2007) has largely recognized the difficulties inherent with measuring socioeconomic status and has called for psychologists to consider this construct carefully in research and practice. A recent review suggested that the use of composite measures of socioeconomic status (e.g., the Hollingshead Index of Social Position) are inappropriate as they are unable to pinpoint the driving force for differences in data (Diemer et al., 2012). Rather, these measures compile multiple aspects into one score (i.e., parental education, household income, occupational prestige, etc.) and tell the user little about how each specific aspect of socioeconomic status is changing the results. Thus, the literature suggests that a more appropriate strategy is to ask multiple questions relating to different aspects of socioeconomic status and to analyze these separately to ensure that important information is not lost during analyses (Diemer et al., 2012). 
To summarize, both socioeconomic status and executive functioning have clear, far-reaching effects on many areas of child development including memory and, without including them both, it would be difficult to ascertain the true contribution of one towards false memory production.

\section{Semantic knowledge.}

Semantic or verbal fluency tasks are those that require participants to name as many objects as they can that fit into a category within some time limit (Lezak, 1995) or by categorizing pictorial images. In adults, links have been made between semantic fluency and false memory production. Specifically, Koutsaal and colleagues (2003) had healthy younger and older adults study and then identify ambiguous (e.g., drawn and then slightly altered via software) pictures of common items. In some conditions the pictures were labeled with the item's category prior to item presentation while in other conditions the objects went unlabeled. They found that older adults in the labeled condition were more prone to false recognition and identified previously unseen objects as studied objects. Gold and colleagues (2007) mimicked this procedure and noted similar results for Alzheimer's disease patients; those with Alzheimer's disease tended to identify more objects as previously seen, resulting in higher rates of false recognition. The authors suggested that the increase in false recognition may be due to dysfunction in either the hippocampus at memory retention or the prefrontal cortex at memory retrieval. Joubert and colleagues (2010) noted cortical degeneration of the anterior temporal lobe and the inferior prefrontal cortex in patients with amnestic mild cognitive impairment and in those with Alzheimer's disease, partially supporting Gold and colleague’s (2007) suggestions. In another study with participants who ranged from young adult to older 
adults with mild dementia of the Alzheimer's type, there was an increase noted in false recall as a function of age and dementia, as well as a proportional increase in false recall to correct recall with age and dementia (Watson, Balota, \& Sergent-Marshall, 2001).

Several studies have aimed to identify links between brain disease or developmental disorder with verbal fluency (e.g., Bourke et al., 2011; Anderson et al., 2002). This is accomplished typically by administering the COWAT and having children name as many items as they can starting with a specific letter (e.g., F, A, or S; Benton, Hamsher, \& Sivan, 1983). For example, Anderson and colleagues (2002) showed that children with frontal lesions did comparatively worse than children with phenylketonuria, hydrocephalus, or control children. This suggests the importance of the frontal lobe in verbal fluency in children as well. Children with heavy prenatal alcohol exposure performed significantly worse than counterparts with ADHD and control on the COWAT letter fluency test. In semantic (category) fluency, children exposed to alcohol prenatally continued to have a significantly worse performance than peers with ADHD and marginally worse than the control group (Vaurio, Riley, \& Mattson, 2008). Additionally, a trending relationship between severity of hypoxia and verbal fluency was noted among children with varying degrees of sleep disordered breathing (Bourke et al., 2011).

Of note, no studies known to this author have examined how semantic knowledge specifically may predict false memories in typically developing children and adolescents using word lists. Importantly, if semantic knowledge is heavily relied upon, false recall and recognition may be more common in children and adolescents.

The current study will examine executive functioning and false memory induction in children with at least average intelligence. Specifically, three aspects of executive 
functioning will be examined: working memory, cognitive flexibility, and inhibition. Two age groups of children will be included in order to examine whether executive functioning impacts the expected pattern of developmental reversals in false memories. As the aforementioned literature suggests, socioeconomic status is an important consideration for both false memory and executive functioning. Thus, socioeconomic status will also be examined as a potential mediator in the relationship between executive functioning and false memory production. Additionally, semantic knowledge will be considered as a driving force in this relationship.

\section{Hypotheses and Exploratory Questions}

\section{Hypothesis 1 and 2}

Younger children (ages 7 and 8) will have lower false recall rates of the critical lure in the DRM task than older children (ages 12 and 13). Older children will, however, perform more accurately on the recognition task.

\section{Rationale.}

The conclusion in DRM research is that younger children will be less likely to falsely recall the critical lures and older children will have better recognition on the DRM recognition task (Howe, Toth, \& Cicchetti, 2011; Metzger et al., 2008; Sugrue \& Hayne, 2006).

\section{Hypothesis 3 and 4}

Children with better executive functioning will perform more accurately on the recognition task, meaning that they will accurately recognize a greater number of previously presented words, and will make fewer recognition errors involving never presented words. 


\section{Rationale.}

Children with better executive functioning skills (inhibition, working memory, and cognitive flexibility) may also be better able to resist false responses and discount them as words not seen on DRM lists.

\section{Hypothesis 5}

Children from higher socioeconomic status backgrounds will perform more accurately on the DRM recognition task.

\section{Rationale.}

Howe and colleagues (2004) found that children from low socioeconomic status backgrounds performed significantly worse than children from middle socioeconomic status backgrounds on a DRM recognition task.

\section{Exploratory Question 1}

Will socioeconomic status predict false memories for the critical lure? Howe and colleagues (2004) examined false memory responses to the critical lure at recall and did not find significant differences between low and middle socioeconomic status children.

\section{Exploratory Question 2}

Will socioeconomic status mediate the relationship between executive functioning and false memories, if one is found to exist in the above analyses?

\section{Exploratory Question 3}

Will performance on the COWAT account for the differences in memory performance (i.e., will semantic processing skills account for false memory production)? 


\section{Method}

\section{Participants}

IRB approval was obtained from West Virginia University. Participants $(N=62)$ included children from two age groups; middle childhood (ages 7 and 8 ; $2^{\text {nd }}$ and $3^{\text {rd }}$ grade; $n=30$ ) and early adolescents (ages 12 and $13 ; 7^{\text {th }}$ and $8^{\text {th }}$ grade; $n=32$ ). These age groups will be described as “younger” and “older” children in subsequent results and discussion. One younger child's data was removed from analyses as this child's data were deemed uninterpretable due to parent interjections and interruptions throughout testing. Two children had a WASI-II score in the below average range (FSIQ < 85) and were not included in analyses. Additionally, several children $(n=7)$ were noted as having a history of a psychological disorder $(\mathrm{ADHD}=4$, Learning Disorder $=1$, Sensory Processing Disorder $=1$, Tourette's Syndrome $=1$ ). These children were ultimately included in analyses as their results on measures of intellectual ability and executive functioning did not differ significantly from their peers (all ps > .05). Thus, the number of older children included was $n=31$ and younger children was $n=28$. Groups were relatively even with regard to gender (total males $=32$, females $=27)$ and most were Caucasian $(n=57$;

93.2\%). Children were recruited from the greater Morgantown and central/northern Vermont communities and came from a range of socioeconomic status backgrounds (e.g., Gross Family Income range $=\$ 0-\$ 14,999$ to $\$ 200,000$ or more; $M=7.34, S D=2.892$; for reference, $7=\$ 90,000-\$ 99,999,8=\$ 100,000-\$ 124,999)$. No geographic differences were noted with regard to gross family income or child FSIQ ( $p$ s $>.05$ ), however a difference was noted in age and maternal education with older children being recruited from the Morgantown community $(t=2.187, p=.033)$ and mothers from the 
Morgantown community having higher education $(t=2.571, p=.0064)$. Of the 59 participants, 18 of them were sibling pairs. Analyses regarding sibling effects suggested very low effect sizes for all of the false memory outcome variables (Cohen's $d$ s range $=$ .040 to .052). Table 1 includes a complete breakdown of demographic information by younger and older child age groups.

\section{Materials}

\section{DRM word lists.}

The six normed lists from Metzger and colleagues (2008; modified from Roediger \& McDermott, 1995) were included. These lists were modified to increase the chance that young children were familiar with each word in the presented list. Each of the 6 lists contained eight words. These materials were selected because they contain words that are normed for children in this age range and because the expected patterns of memory findings consistent with the majority of other studies occurred using these stimuli (developmental reversals in false memory, developmental reversals in recognition).

\section{Delayed Recognition}

The same DRM word lists were incorporated into a recognition task to assess delayed memory for critical lures. A word list containing 108 words was created using validated DRM lists, both presented and unpresented (Metzger et al., 2008).

\section{Semantic knowledge.}

As a test to see whether semantic and conceptual knowledge is the true driving force behind the developmental reversal phenomenon, children were asked to complete the Controlled Oral Word Association Test (COWAT; Benton, Hamsher, \& Sivan, 1983). In order to establish that participants in this study viewed the basic-level terms as being 
categorical exemplars or associates to the critical lure, the first ten participants completed a matching task where they were asked to read a word and then choose the category it best matched with. This was created using all of the words from the DRM lists as well as words from other normed DRM lists not used in this study. Since participants performed well on this task ( $M=80.7 \%$ correct matches), we substituted this task for a simpler, briefer task, the COWAT. The COWAT allowed for the examination of a semantic activation correlate to false memories. Essentially, since the participants were able to perform well on this task, it indicated that some semantic knowledge existed and that the words could be judged as belonging to their appropriate category. The COWAT has an added bonus of pre-existing norms for most of these age groups. However, no norms exist for age 13, so age 13 data for this study was calculated based upon the 12-year-old norms (Halperin et al., 1989). Children were asked to list verbally all of the animals they could in one minute (norms exist) followed by all of the vegetables they could in one minute (no norms currently exist).

\section{Intelligence.}

Previous research has suggested that poor performance on tests of intellectual ability may be related to poorer executive functioning (Barbey et al., 2012; Brydges et al., 2012) and memory (Allen, Martin, \& Martin, 2012), though this research has been mixed (Arffa, 2007; Friedman et al., 2006; Ackerman et al., 2005). IQ was also used as a ruleout; if participants scored below one standard deviation from the average they were removed from further analyses. Each participant was administered the two-subtests form of the Wechsler Abbreviated Scales of Intelligence, Second Edition (WASI-II; Wechsler, 2011). Each participant completed the Matrix Reasoning and Vocabulary subtests. These 
two subtests load onto a Full Scale IQ score to give an estimate of intellectual ability. Matrix Reasoning is an assessment of perceptual reasoning skills and Vocabulary is a measure of verbal comprehension.

\section{Executive functioning.}

The Digit Span subtest of the Wechsler Intelligence Scale for Children, Fourth Edition (WISC-IV; Wechsler, 2004) served as a test of working memory, an important aspect of executive functioning. In addition, two measures from the Developmental Neuropsychological Assessment, Second Edition (NEPSY-II; Korkman, Kirk \& Kemp, 2007a, 2007b) were administered to assess what Diamond (2013) deemed as the core components to executive functioning; working memory, inhibition, and cognitive flexibility. As stated, working memory was covered in the Digit Span subtest of the WISC-IV, specifically Digit Span Backwards. For inhibition, the Inhibition subtest of the NEPSY-II was administered. Inhibition requires the child to give a novel response in favor of an automatic response. Specifically, they must first say the exact shape or directional arrow they see on a screen, then they must inhibit the automatic response to say the opposite. Finally, for cognitive flexibility, Animal Sorting of the NEPSY-II was administered. This task requires the child to sort cards into two piles, based upon sorting rules, of four cards each.

\section{Demographics.}

After the parent and child completed the consent and assent forms, respectively, the parent was asked to fill out a questionnaire regarding demographics, income, and parent education to serve as a proxy for socioeconomic status. Parents were also asked to 
endorse or deny nonspecific history of psychological disorder, head injury, or $\mathrm{O}_{2}$ deprivation history for their child.

\section{Procedure}

Following parental and consent and child assent one parent completed the demographic form. Children were then administered the WASI-II and executive functioning assessment battery on an individual basis by a graduate student (all completed by PS). First, they completed the WASI-II subtests; Matrix Reasoning and Vocabulary. Following this task, each child then completed the two tests of executive functioning of the NEPSY-II, Animal Sorting and Inhibition. They completed the WISCIV Digit Span subtest following the NEPSY-II. Both the NEPSY-II tests and the Digit Span subtest were completed on Apple iPads using Q-Interactive software (NCS Pearson, Inc., 2016). One iPad was designated as the Examiner iPad and contained software for creating clients, designing test batteries, conducting the assessments, and reviewing results. The other iPad was designated as the Client iPad and was only used for the Inhibition subtest of the NEPSY-II. The Client iPad displayed the sample and test patterns of shapes or arrows, which the child was required to identify. During testing, results screens were skipped so as to avoid any bias introduction into the study.

Next, children were given basic instructions regarding the DRM memory task (Metzger et al., 2008). They were told that words would be presented on an audio recorder and that they would need to try to remember as many words as they can once the recording is done. Accordingly, they were instructed to listen carefully prior to the tape recorder being turned on. Participants listened to each of the 6 word lists containing 8 words each on a recording. Words were read clearly and loudly by this author at a speed 
of one word every two seconds. After each list, the child was immediately asked to recall as many words as they could. Afterwards, the second list was presented, followed by recall for that list. This continued in such a pattern until all six lists had been read. Similar to previous research (e.g., Holliday et al., 2011), children participated in a filler task for 30-seconds involving addition problems in order not to interfere with semantic processing.

Finally, for the delayed recognition task, children were read some words that were previously presented and some new words that were not previously presented out loud. They were then asked to verbally respond 'yes' to words they were presented with previously and 'no' to words that they believed were not presented on the audio recording. This recognition list included 108 words, as per Metzger and colleagues (2008); (a) 48 previously presented and 60 previously never presented words, including four of the critical lures. Children were instructed not to guess and to only say 'yes' to the words they are certain they heard, as per Roediger and McDermott's (1995) instructions. Children were then administered the semantic knowledge matching test (participants 1-10) or the COWAT (the remaining 52 participants). Finally, they were debriefed on the nature of the study. Participants received a small compensation (\$20) as a thank you for participating in the study.

\section{Results}

\section{Data Analyses: Overview}

Because younger children tend to engage in positive response bias (saying yes) more often, raw hit rates for recognition may not always be appropriate (e.g., Brainerd et al., 2002). Therefore, a variation of signal detection will be used, specifically $A$ '. 
Snodgrass and Corwin (1988) first introduced this technique as a method for correcting biased responding in memory recognition tasks. These formulas result in a manner such that when $A^{\prime}=0.5$, there is a lack of true recognition (accepting targets more often than distractors) or a lack of semantic false recognition (accepting distractors that foil the studied material over unrelated distractors). When $A^{\prime}=1$, perfect true or false recognition exists. A' will be calculated from participant responses on the recognition task. Of note for this study are the $A$ ' for true positive responses (e.g., saying “Yes” when the word was previously presented, a “Hit”) and for false positives (e.g., saying "Yes” when the word was not previously presented, a “False Alarm”).

Four separate multiple regressions were run to assess the relation between age, socioeconomic status (e.g., gross family income and parent education), cognitive abilities, and executive functioning on 1) proportion of critical lure production at recall, 2) critical lure memory on the recognition task, 3) $A^{\prime}$ for true positive responses and 4) $A^{\prime}$ for false positive responses. When mediation analyses were indicated, stepwise regressions were used to identify socioeconomic status as a mediator in the relationship between measures of executive functioning and false memory. Predictors were normally distributed and fit the assumptions necessary for regression analyses.

\section{Immediate False Memories: Free Recall Memory Accuracy}

Table 2 includes means and standard deviations for participant tasks. To assess immediate false memory recall, the proportion of critical lures remembered during recall was calculated. The proportion was calculated to take into account the number of words accurately remembered during recall as well. For example, if a child remembered 35 of the 48 possible words, and also remember 3 of the critical lures, then the proportion of 
critical lure recall would be .0789 (e.g., 3/38). Higher proportions represent increased false memory for critical lures. Results of the regression analysis suggested that each of the measured aspects of intellectual ability, as well as performance on the Animal Sorting subtest of the NEPSY-II and mother's highest degree achieved were related to critical lure recall proportion. Age of the participant (entered as a categorical variable to assess whether developmental reversals of false memory exist in this sample) did not appear to predict performance on the free recall task $(t=-.955, p=.348)$. Better performance on Vocabulary and Matrix Reasoning predicted higher critical lure proportion (Vocabulary: $t$ $=2.572, p=.016$; Matrix Reasoning: $t=2.543, p=.017)$. Interestingly, higher overall FSIQ-2 predicted lower critical lure recall $(t=-2.662, p=.013)$. On the Animal Sorting subtest, the total number of correct sorts was predictive of higher critical lure recall proportion $(t=2.158, p=.040)$. Finally, higher maternal educational achievement was predictive of higher critical lure recall proportion $(t=2.683, p=.012)$. Table 3 summarizes the results of these analyses. All of the other aspects of executive functioning (e.g., other scales on the Inhibition subtest, Digit Span Backwards), as well as the results of the COWAT, revealed non-significant predictive value.

Due to the significant relation of the measures of executive functioning (e.g., Animal Sorting number of correct sorts scaled score) and mother's education to critical lure recall proportion, early steps to test the assumptions of mediation analysis were conducted with the executive functioning measure as the independent variable, mother's education as the mediating variable, and critical lure recall as the dependent variable. However, in these analyses, none of the predictor variables were significantly related to 
critical lure recall on their own (all $p s>.05$ ), suggesting that this mediation was not appropriate (Figure 1).

\section{Delayed False Memories for the Critical Lure: Recognition}

As a method of assessing delayed false memories, the number of critical lures that were responded to with a positive (Yes) response was calculated. This positive response was indicative of the participant saying they had heard the critical lure previously on the word lists. Thus, a higher number of critical lures recognized during this task would suggest more false memories. No significant predictions emerged from this analysis in regards to age, socioeconomic status, executive functioning, or semantic knowledge (Table 6).

\section{Hit Rate on Recognition}

Signal detection was used to calculate the "Hit” rate (e.g., accurate identification) on the recognition task. Again, signal detection was used to take into the account the tendency of young children towards a positive response bias (e.g., Brainerd et al., 2002). The resulting proportion from the signal detection correction was used as the outcome variable. In these analyses, only age and gross family income emerged as significant predictors of Hit rate. Specifically, older participants tended to have higher "Hit” rates than younger children $(t=2.316, p=.028)$. Additionally, participants whose families had higher gross family income had lower Hit rates $(t=-3.011, p=.006)$. No significant predictions emerged for any measures of executive functioning or semantic knowledge (Table 7).

\section{False Alarm Rate on Recognition}


Signal detection was also used to calculate the False Alarm rate (e.g., false memories) on the recognition task. Again, the resulting proportion from the signal detection correction was used as the outcome variable. In these analyses, only the Inhibition Switching Combined score on the NEPSY-II showed predictive capabilities. Participants who performed better on this aspect of the Inhibition subtest showed fewer false memories on the delay $(t=-2.260, p=.032)$. No significant predictions emerged for any other measures of executive functioning, age, socioeconomic status, or semantic knowledge (Table 8).

\section{Discussion}

This study aimed at evaluating the effects that executive functioning may have on false memory production. Multiple instances where executive functioning was an important predictor of false memory are highlighted by the current results. These results could shed light on different methods to use or actions to take when engaging children in a forensic interview following their witnessing of a crime.

Results were mixed in regards to executive functioning. Cognitive flexibility and inhibition were both predictive of false recognition. The total number of sorts identified in the Animal Sorting subtest of the NEPSY-II predicted critical lure recall, with higher scores being associated with increased false recall. This may suggest that children who were less rigid in their approach to the Animal Sorting task (i.e., children who had more cognitive flexibility) may have more fluidly recalled words without attending to whether they were actually heard or if they were just similar, semantically. This approach may make children more prone to memory errors. This result can also be viewed from the lens of Fuzzy Trace Theory; participants who identified more themes (i.e., the "gist”) had 
higher false recall. In regards to inhibition, children who performed well on Inhibition Switching Combined (which combines the scaled scores of completion time and errors) had fewer false memories at recognition. This task is incredibly complex and requires strong inhibitory skills. Thus, this subset of children who performed well on this task were also well set up to be able to discount the critical lure and have fewer false memories at recognition. Working memory appeared to play no significant role with this sample of participants. However, the use of Digit Span backwards as a measure of working memory is limited.

Critical lure proportion at recall was predicted by all aspects of IQ measurement. Better performance on both the Vocabulary and the Matrix Reasoning scales predicted higher proportion of critical lure memory (i.e., higher false memory rates) immediately after words were presented. One explanation could be that if a child has a more extensive vocabulary, they may make connections between words more easily, thus leading to the critical lure memory when it was not presented. This finding was also noted in previous research as well (e.g., Howe, Toth, \& Cicchetti, 2011). The similar association between the visuospatial subtest of Matrix Reasoning could be explained by children creating some sort of visual representation of the words they are attempting to remember. Children with higher visuospatial skills could have thus been creating some sort of pictorial representation of the words and associating them in a similar manner. This result would actually be in opposition to previous studies noting that lower perceptual IQ is associated with increased false memory, though at recognition (Zhu, 2010a). The immediacy of false memory at recall may be an important factor here. 
Surprisingly, false memories at recall and recognition were not related to normed results on the COWAT. Previous research with adults had suggested that semantic fluency would be important in recognition (e.g., Koutsaal et al., 2003). Given that no studies have been done to assess this relationship prior to the current study and because, intuitively, this relationship seems reasonable, future research should continue to consider semantic fluency as a potential predictor to false memories.

Children with a lower overall FSIQ-2 predicted higher critical lure memory at recall. This is especially interesting considering the two scales which comprise FSIQ-2 (Vocabulary and Matrix Reasoning) were associated with critical lure memory in the opposite direction. This may be due to the additive nature of how FSIQ-2 is calculated. Individually, having higher scores on Vocabulary and Matrix Reasoning resulted in lower critical lure memory, but those participants who were high on both subtests tended to remember the critical lure more often. Zhu (2010a) noted that having a lower IQ was associated with higher false memory at recognition. Again, the immediacy of false recall could be the reason for this difference.

Our hypothesis for age being an important predictor of false memory was partially supported. Specifically, there was no significant relationship noted between age and critical lure recall. Thus, there were no developmental reversals in false memory observed in this sample (Holliday et al., 2011). An age difference in recognition accuracy was revealed with older children having a higher "Hit" rate than younger children. This result is consistent with previous research showing that older children and adults have a larger general memory capacity than younger children (Howe, Toth, \& Cicchetti, 2011; Metzger et al., 2008). 
A major strength of this study was the method in which socioeconomic status was assessed. Rather than combining different important aspects of socioeconomic status into a single score, gross family income, maternal, and paternal education were included as individual variables in analyses to assess their unique contribution to outcomes. As a result of this method, the relationship between critical lure proportion recall and maternal education was identified. However, no major differences were noted on any aspect of socioeconomic status for false memories at recognition. This is in contrast to the findings of Howe and colleagues (2004). This difference may be due to the manner in which socioeconomic status was defined, as Howe and colleagues (2004) grouped participants based on low- or middle-socioeconomic status. This grouping was based purely on need for public assistance, however, and did not grasp at other aspects of SES (e.g., education). Additionally, despite this relationship emerging between critical lure recall proportion, an aspect of executive functioning (e.g., Animal Sorting Number of Sorts) and maternal education, there was no significant mediation to speak of. This points to other variables potentially driving this relationship that were unmeasured (e.g., other aspects of socioeconomic status like cost-of-living, hours worked by parents, or per capita income) and begs for future investigation.

This study is not without limitations. There were location differences noted between children recruited from West Virginia and children recruited from Vermont. Specifically, children from the Morgantown community were older and tended to have mothers who were more highly educated $(p s<.05)$. A sampling bias may be to blame for these differences given that several of the participants from the Morgantown community were University-affiliated. However, despite these location differences, there were no 
differences between these two locations in regards to any of the outcome variables measured. Further, this group was limited in racial/ethnic diversity and came from primarily well-educated, higher socioeconomic status backgrounds. Compared to previous studies, the children in this study also performed more accurately (Metzger et al., 2008). More studies in this area should include a broader sample of children and adolescents so stronger conclusions can be drawn.

This study did not assess for specific environmental factors that may affect memory, aside from previous head injury, mental health diagnosis, anoxia/hypoxia, and socioeconomic status. Other areas to consider for future research may include prenatal drug or alcohol exposure, specific instances of trauma, typical sleep quality/quantity, and chronic medical problems. There was also no specific assessment of effort with participants, so it is difficult to say whether participants were performing at their best aside from clinical judgment. This could be solved in the future with a brief version of the word recognition tests used in this study, much like the Test of Memory Malingering (TOMM; Tombaugh, 1996). DeRight and Carone’s (2015) recently published review on effort testing in children made recommendations regarding the use of these tests, which are often ignored with children and pediatric populations. Additionally, a parent-report of executive functioning [e.g., the Behavior Rating Inventory of Executive Functioning (BRIEF); Gioia et al., 2000] may have provided beneficial information should children have been giving low effort.

Child temperament may also be an important aspect that went unmeasured in this study. Temperament is defined as the method in which a child regulates processes and their reactivity to situations (Rothbart \& Derryberry, 1981). Considering the higher-order 
nature of these processes (much like those involved in executive functioning) this would be important to consider in future research. Noguera and colleagues (2015) found that children with better inhibition skills attended to words they were supposed to remember longer than words they were supposed to ignore, whereas children low in this trait attended to these words equally.

Measurement of executive functioning and IQ were limited in this study. The WASI-II two-subtest measure of IQ is brief; this is beneficial for research purposes, but may not have been the most comprehensive way to measure IQ. The use of this brief IQ measure may also have been the reason for the strange findings regarding IQ and recall. Additionally, the NEPSY-II assesses two aspects of executive functioning: inhibition and cognitive flexibility. The addition of the WISC-IV Digit Span subtest added a working memory measure for this study. There are many of aspects of executive functioning (e.g., initiation, planning, attention) that may be important in the creation of false memories and should be considered in future studies.

These results point to the importance of aspects of executive functioning in false memory production. Further research is needed to point to practical and logistic implications of these results in child witness interviewing. All children should be interviewed using the most empirically validated forensic methods (e.g., the Cognitive Interview; Fisher \& Geiselman, 1992; Geiselman, Fisher, MacKinnon, \& Holland, 1985) but this may become increasingly important for children who may be lower than their peers in aspects of intelligence and executive functioning. 


\section{References}

Ackerman, P. L., Beier, M. E., \& Boyle, M. O. (2005) Working memory and intelligence: the same or different constructs? Psychological Bulletin, 131, 30-60.

Allen, C. M., Martin, R. C., \& Martin, N. (2012). Relations between short-term memory deficits, semantic processing, and executive function. Aphasiology, 26, 428-461.

American Psychological Association,Task Force on Socioeconomic Status. (2007). Report of the APA Task Force on Socioeconomic Status. Washington, DC: American Psychological Association.

Anderson, V. A., Anderson, P., Northam, E., Jacobs, R., \& Mikiewicz, O. (2002). Relationships between cognitive and behavioral measures of executive function in children with brain disease. Child Neuropsychology, 8, 231-240.

Arffa, S. (2007). The relationship of intelligence to executive function and non-executive function measures in a sample of average, above average, and gifted youth. Archives of Clinical Neuropsychology, 22, 969-978.

Barbey, A. K., Colom, R., Solomon, J., Krueger, F., Forbes, C., \& Grafman, J. (2012). An integrative architecture for general intelligence and executive function revealed by lesion mapping. Brain: a Journal of Neurology, 135, 1154-1164.

Baron, R. M. and Kenny, D. A. (1986). The moderator-mediator variable distinction in social psychological research - Conceptual, strategic, and statistical considerations. Journal of Personality and Social Psychology, 51, 1173-1182.

Benton, A. L., Hamsher, de S. K., \& Sivan, A. B. (1983). Multilingual aplasia examination (2nd ed.). Iowa City, IA: AJA Associates

Bixter, M. T., \& Daniel, F. (2013). Working memory differences in illusory recollection 
of critical lures. Memory and Cognition, 41, 716-725.

Blair, C. (2010). Stress and the development of self-regulation in context. Child Development Perspectives, 4, 181-188.

Blair, C., Granger, D. A., Willoughby, M., Mills-Koonce, R., Cox, M., Greenberg, M. T., \& The Family Life Project Investigators. (2011). Salivary cortisol mediates effects of poverty and parenting on executive functions in early childhood. Child Development, 82, 1970-1984.

Blewitt, P., \& Krackow, E. (1992). Acquiring taxonomic relations in lexical memory: The role of superordinate category labels. Journal of Experimental Child Psychology, 54, 37-56.

Bourke, R., Anderson, V., Yang, J. S. C., Jackman, A. R., Killedar, A., Nixon, G. M., Davey, M. J., Walker, A. M., Trinder, J., \& Horne, R. S. C. (2011). Cognitive and academic functions are impaired in children with all severities of sleep-disordered breathing. Sleep Medicine, 12, 489-496.

Brainerd, C. J., Holliday, R. E., \& Reyna, V. F. (2004). Behavioral measurement of remembering phenomenologies: So simple even a child can do it. Child Development, 75, 505-522.

Brainerd, C. J., \& Reyna, V. F. (2004). Fuzzy-trace theory and memory development. Developmental Review, 24, 396-439.

Brainerd, C. J., \& Reyna, V. F. (2005). The science of false memory. New York: Oxford University Press.

Brainerd, C. J., Reyna, V. F., \& Forrest, T. J. (2002). Are young children susceptible to the false-memory illusion? Child Development, 73, 1363 - 1377. 
Brainerd, C. J., Reyna, V. F., \& Howe, M. L. (2009). Trichotomous processes in early memory development, aging, and cognitive impairment: A unified theory. Psychological Review, 116, 783-832.

Brainerd, C.J., Reyna, V.F., Petersen, R.C., Smith, G.E. \& Taub, E.S. (2011). Is the Apolipoprotein E genotype a biomarker for mild cognitive impairment? Findings from a nationally representative study. Neuropsychology, 25, 679-689.

Brainerd, C. J., Reyna, V. F., \& Poole, D. A. (2000). Fuzzy-trace theory and false memory: Memory theory in the courtroom. In D. F. Bjorklund (Ed.), False memory creation in children and adults: Theory, research, and implications (pp. 93-127). Mahwah, NJ US: Lawrence Erlbaum Associates Publishers

Brainerd, C. J., Reyna, V. F., Wright, R., \& Mojardin, A. H. (2003). Recollection rejection: False memory editing in children and adults. Psychological Review, 110, 762-784.

Bruck, M., \& Ceci, S. J. (1999). The suggestibility of children’s memory. Annual Reviews of Psychology, 50, 419-439.

Brydges, C. R., Reid, C. L., Fox, A. M., \& Anderson, M. (2012). A unitary executive function predicts intelligence in children. Intelligence, 40, 458-469.

Buss, C., Davis, E. P., Shahbaba, B., Pruessner, J. C., Head, K., \& Sandman, C. A. (2012). Maternal cortisol over the course of pregnancy and subsequent child amygdala and hippocampus volumes and affective problems. Proceedings of the National Academy of Sciences, 109, e1312-e1319.

Carlson S. M. \& Meltzoff A. N. (2008). Bilingual experience and executive functioning in young children. Developmental Science, 11, 282-298. 
Carneiro, P., Albuquerque, P., \& Fernandez, A. (2009). Opposite developmental trends for false recognition of basic and superordinate names. Memory, 17, 411-427.

Ceci, S. J., Huffman, M. L. C., Smith, E., \& Loftus, E. F. (1996). Repeatedly thinking about a non-event: Source of misattributions among preschoolers. In K. Pezdek \& W. P. Banks (Eds.), The recovered memory/false memory debate (pp. 225-244). San Diego, CA: Academic Press.

Ceci, S. J., Ross, D. F., \& Toglia, M. P. (1987). Suggestibility of children’s memory: Psycholegal implications. Journal of Experimental Psychology: General, 116, $38-49$.

Cicchetti, D., \& Valentino, K. (2006). An ecological transactional perspective on child maltreatment: Failure of the average expectable environment and its influence upon child development. In D. Cicchetti \& D. J. Cohen (Eds.), Developmental psychopathology: Vol. 3. risk, disorder, and adaptation (2nd ed., pp. 129-201). New York: Wiley.

Davis, E. P., Sandman, C. A., Buss, C., Wing, D. A., \& Head, K. (2013). Fetal Glucocorticoid exposure is associated with preadolescent brain development. Biological Psychiatry, 74, 647-655.

Deese, J. (1959). On the prediction of occurrence of particular verbal intrusions in immediate recall. Journal of Experimental Psychology, 58, 17-22.

Diamond, A. (2013). Executive functions. Annual Review of Psychology, 64, 135-168.

DeRight, J., \& Carone, D. A. (2015). Assessment of effort in children: A systematic review. Child Neuropsychology: A Journal on Normal and Abnormal Development in Childhood and Adolescence, 21, 1-24. 
Diemer, M. A., Mistry, R. S., Wadsworth, M. E., López, I., \& Reimers, F. (2012). Best Practices in conceptualizing and measuring social class in psychological research. Analyses of Social Issues and Public Policy, 00, 1-37.

Flanagan, D. P., \& Kaufman, A. S. (2009). Essentials of WISC-IV assessment (Vol. 56). John Wiley \& Sons.

Fisher, R. P., \& Geiselman, R. (1992). Memory-enhancing techniques for investigative interviewing: The cognitive interview. Springfield, IL England: Charles C Thomas, Publisher.

Friedman, N. P., Miyake, A., Corley, R. P., Young, S. E., DeFries, J. C., \& Hewitt, J. K. (2006). Not all executive functions are related to intelligence. Psychological Science, 17, 172-179.

Geiselman, R. E., Fisher, R. P., MacKinnon, D. P., \& Holland, H. L. (1985). Eyewitness memory enhancement in the police interview: Cognitive retrieval mnemonics versus hypnosis. Journal of Applied Psychology, 70, 401-412.

Ghetti, S., Qin, J., \& Goodman, G. S. (2002). False memories in children and adults: Age, distinctiveness, and subjective experience. Developmental Psychology, 38, 705718.

Gioia, G. A., Isquith, P. K., Guy, S. C., \& Kenworthy, L. (2000). The behavior rating of executive function. Odessa, FL: PAR.

Gold, C. A., Marchant, N. L., Koutsaal, W., Schacter, D. L., \& Budson, A. E. (2007). Conceptual fluency at test shifts recognition response bias in Alzheimer's disease: Implications for increased false recognition. Neuropsychologia, 45, 2791-2801.

Goodman, G. S., Ogle, C. M., Block, S. D., Harris, L. S., Larson, R. P., Augusti, E., 
Cho, Y. I., Beber, J., Timmer, S. \& Urquiza, A. (2011). False memory for trauma related Deese-Roediger-McDermott lists in adolescents and adults with histories of child sexual abuse. Development and Psychopathology, 23, 423-428.

Hackman, D. A., \& Farah, M. J. (2009). Socioeconomic status and the developing brain. Trends in Cognitive Sciences, 13, 65-73.

Hackman, D. A., Farah, M. J., \& Meaney, M. J. (2010). Socioeconomic status and the brain: Mechanistic insights from human and animal research. Nature Reviews Neuroscience, 11, 651-659.

Halperin, J. M., Healey, J. M., Zeitchik, E., Ludman, W. L., \& Weinstein, L. (1989). Developmental aspects of linguistic and mnestic abilities in normal children. Journal of Clinical and Experimental Neuropsychology, 11, 518-528.

Holliday, R. E., Brainerd, C. J., \& Reyna, V. F. (2011). Developmental reversals in false memory: Now you see them, now you don't! Developmental Psychology, 47, 442-449.

Holliday, R. E., Reyna, V. F., \& Brainerd, C. J. (2008). Recall of details never experienced: Effects of age, repetition, and semantic cues. Cognitive Development, 23, 67-78.

Howe, M. L. (2005). Children (but not adults) can inhibit false memories. Psychological Science, 16, 927-931.

Howe, M. L. (2006). Developmentally invariant dissociations in children's true and false memories: Not all relatedness is created equal. Child Development, 77, 11121123.

Howe, M. L. (2008). Visual distinctiveness and the development of children's false 
memories. Child Development, 79, 65-79.

Howe, M. L., Cicchetti, D., Toth, S. L., \& Cerrito, B. M. (2004). True and false memories in maltreated children. Child Development, 75, 1402-1417.

Howe, M. L., Cicchetti, D., \& Toth, S. L. (2006). Children's basic memory processes, stress, and maltreatment. Development and Psychopathology, 18, 759-769.

Howe, M. L., Toth, S. L., \& Cicchetti, D. (2011). Can maltreated children inhibit true and false memories for emotional information? Child Development, 82, 967-981.

Howe, M. L., Wimmer, M. C., \& Blease, K. (2009). The role of associative strength in children's false memory illusions. Memory, 17, 8-16.

Joubert, S., Brambati, S. M., Ansado, J., Barbeau, E. J., Felician, O., Didic, M., Lacombe, J., Goldstein, R., Chayer, C., \& Kergoat, M-J. (2010). The cognitive and neural expression of semantic memory impairment in mild cognitive impairment and early Alzheimer’s disease. Neuropsychologia, 48, 978-988.

Khanna, M. M., \& Cortese, M. J. (2009). Children and adults are differentially affected by presentation modality in the DRM paradigm. Applied Cognitive Psychology, 23, 859-877.

Korkman, M., Kirk, U., \& Kemp, S.L. (2007a). NEPSY II. Administrative manual. San Antonio, TX: Psychological Corporation.

Korkman, M., Kirk, U., Kemp, S.L. (2007b). NEPSY II. Clinical and interpretative manual. San Antonio, TX: Psychological Corporation.

Krackow, E., Kania, K., \& Travers, R. M. (2013). Does negative mood confer a recall advantage for negative life events? Imagination, Cognition, and Personality, 32, 291-305. 
Koutstaal, W., Reddy, C., Jackson, E. M., Prince, S., Cendan, D. L., \& Schacter D. L. (2003). False recognition of abstract versus common objects in older and younger adults: Testing the semantic categorization account. Journal of Experimental Psychology: Learning, Memory, and Cognition, 29, 499-510.

Lezak, Muriel Deutsch (1995). Neuropsychological assessment. Oxford [Oxfordshire]: Oxford University Press.

Lindsay, D. W., \& Johnson, M. K. (1987). Reality monitoring and suggestibility: Children’s ability to discriminate among memories from different sources. In S. J. Ceci, M. P. Toglia, \& D. F. Ross (Eds.), Children’s eyewitness memory (chap. 6). New York: Springer-Verlag.

Loftus, E. F. (1975). Leading questions and the eyewitness report. Cognitive Psychology, 7, 560-572.

Loftus, E. F. (1993). The reality of repressed memories. American Psychologist, 48, 560572.

Loftus, E. F. (2000). Remembering what never happened. In E. Tulving (Ed.), Memory, consciousness, and the brain: The Tallinn Conference (pp. 106-118). New York, NY US: Psychology Press.

Loftus, E. F. (2003). Make-believe memories. American Psychologist, 5, 864-873.

Loftus, E. F. (2005a). Planting misinformation in the human mind. A 30-year investigation of the malleability of memory. Learning and Memory, 12, 361-366.

Loftus, E. F. (2005b). Searching for the neurobiology of the misinformation effect. Learning \& Memory, 12, 1-2.

Loftus, E. F., \& Palmer, J. P. (1974). Reconstruction of automobile destruction: An 
example of the interaction between language and memory. Journal of Verbal Learning \& Verbal Behavior, 13, 585-589.

Loftus, E. F., \& Pickrell, J. E. (1995). The formation of false memories. Psychiatric Annals, 25, 720-725.

Lynn, S., Lock, T., Loftus, E. F., Krackow, E., \& Lilienfeld, S. O. (2003). The remembrance of things past: Problematic memory recovery techniques in psychotherapy. In S. O. Lilienfeld, S. Lynn, J. M. Lohr (Eds.), Science and pseudoscience in clinical psychology (pp. 205-239). New York, NY US: Guilford Press.

Mazzoni, G., \& Memon, A. (2003). Imagination can create false autobiographical memories. Psychological Science, 14, 186-188,

Metzger, R. L., Warren, A. R., Shelton, J. T., Price, J., Reed, A. W., \& Williams, D. (2008). Do children 'DRM' like adults? False memory production in children. Developmental Psychology, 44, 169-181.

NCS Pearson, Inc. (2016). Q-Interactive [computer software]. Pearson Education, Inc.

Noble, K. G., Houston, S. M., Kan, E., \& Sowell, E. R. (2012). Neural correlates of socioeconomic status in the developing human brain. Developmental Science, 15, 516-527.

Noguera, C., Álvarez, D., Carmona, E., \& Parra, L. (2015). Temperament and negative semantic priming in children 7 to 12 years old. Child Neuropsychology: A Journal on Normal and Abnormal Development in Childhood and Adolescence, 21, 302313.

Otgaar, H., \& Candel, I. (2011). Children’s false memories: Different false memory 
paradigms reveal different results. Psychology, Crime, \& Law, 17, 513-528.

Peters, M. J. V., Jelicic, M., Haas, N., \& Merckelbach, H. (2006). Mild executive dysfunctions in undergraduates are related to recollecting words never presented. International Journal of Neuroscience, 116, 1065-1077.

Pezdek, K., \& Hodge, D. (1999). Planting false childhood memories in children: The role of event plausibility. Child Development, 70, 887-895.

Pezdek, K., \& Roe, C. (1997). The suggestibility of children’s memory for being touched: Planting, erasing, and changing memories. Law and Human Behavior, 21, 95-106.

Poole, D. A. (1995). Strolling fuzzy-trace theory through eyewitness testimony (or vice versa). Learning and Individual Differences, 7, 87-93.

Qui, A., Rifkin-Graboi, A., Chen, H., Chong, Y-S., Kwek, K., Gluckman, P. D., Fortier, M. V., \& Meaney, M. U. (2013). Maternal anxiety and infants’ hippocampal Development: timing matters. Translational Psychiatry, 3, 1-7.

Reyna, V. F., \& Brainerd, C. J. (1995). Fuzzy-trace theory: An interim synthesis. Learning And Individual Differences, 7, 1-75.

Reyna, V. F., Holliday, R., \& Marche, T. (2002). Explaining the development of false memories. Developmental Review, 22, 436-489.

Reyna, V. F., Mills, B., Estrada, S., \& Brainerd, C. J. (2007). False memory in children: Data, theory, and legal implications. In M. P. Toglia, J. Read, D. F. Ross, R. L. Lindsay (Eds.), The handbook of eyewitness psychology, Vol I: Memory for events (pp. 479-507). Mahwah, NJ US: Lawrence Erlbaum Associates Publishers.

Roberts, K. P. (2000). An overview of theory and research on children’s source 
monitoring. In K. P. Roberts \& M. Blades (Eds.), Children’s source monitoring (pp. 11-57). Mahwah, NJ: Lawrence Erlbaum Associates Inc.

Roediger, H. L., III, \& McDermott, K. B. (1995). Creating false memories: Remembering words not presented in lists. Journal of Experimental Psychology: Learning, Memory, and Cognition, 21, 803-814.

Roediger, H. L., \& McDermott, K. B. (2000). Tricks of memory. Current Directions in Psychological Science, 9, 123-127.

Rothbart, M. K., \& Derryberry, D. (1981). Development of individual differences temperament. In J. W. Fagen \& J. Colombo (Eds.), Advances in developmental psychology (Vol. 1, pp. 37-86). Hillsdale, NJ: Erlbaum.

Schacter, D. L., Kagan, J., \& Leichtman, M. D. (1995). True and false memories in children and adults: A cognitive neuroscience perspective. Psychology, Public Policy, Law, 1, 411-428.

Snodgrass, J. G., \& Corwin, J. (1988). Pragmatics of measuring recognition memory: Applications to dementia and amnesia. Journal of Experimental Psychology: General, 117, 34-50.

Stadler, M. A., Roediger, H., \& McDermott, K. B. (1999). Norms for word lists that create false memories. Memory \& Cognition, 27, 494-500.

Sugrue, K., \& Hayne, H. (2006). False memories produced by children and adults in the DRM paradigm. Applied Cognitive Psychology, 20, 625-631.

Sugrue, K., Strange, D., \& Hayne, H. (2009). False memories in the DRM paradigm: Age-related differences in lure activation and source monitoring. Experimental Psychology, 56, 354-360. 
Tombaugh, T. N. (1996). Test of Memory Malingering (TOMM). New York: Multi Health Systems, Inc.

Vaurio, L., Riley, E. P., \& Mattson, S. N. (2008). Differences in executive functioning in children with heavy prenatal alcohol exposure or attention-deficit/hyperactivity disorder. Journal of the International Neuropsychological Society, 14, 119-129.

Watson, J. M., Balota, D. A., \& Sergent-Marshall, S. D. (2001). Semantic, phonological, and hybrid veridical and false memories in healthy older adults and in individuals with dementia of the Alzheimer’s type. Neuropsychology, 15, 254-267.

Watson, J. M., Lambert, A. E., Miller, A., \& Strayer, D. L. (2011). The magical letters P, F, C, and sometimes U: The rise and fall of executive attention with the development of prefrontal cortex. In K. L. Fingerman, C. A. Berg, J. Smith, T. C. Antonucci (Eds.), Handbook of life-span development (pp. 407-436). New York, NY US: Springer Publishing Co.

Wechsler, D. (2004). The Wechsler intelligence scale for children-fourth edition. London: Pearson Assessment.

Wechsler, D. (2011) The Wechsler abbreviated scale of intelligence, $2^{\text {nd }}$ edition (WASIII). San Antonio, TX: NCS Pearson.

Zhu, B., Chen, C., Loftus, E. F., Lin, C., He, Q., Chen, C., Li, H., Xue, G., Lu, Z., \& Dong, Q. (2010a). Individual differences in false memory from misinformation: Cognitive factors. Memory, 18, 543-555.

Zhu, B., Chen, C., Loftus, E. F., Lin, C., He, Q., Chen, C., Li, H., Moyzis, R. K., Lessard, J., \& Dong, Q. (2010b). Individual differences in false memory from misinformation: Personality characteristics and their interactions with cognitive 
abilities. Personality and Individual Differences, 48, 889-894.

Zhu, B., Chen, C., Loftus, E. F., Lin, C., \& Dong, Q. (2013). The relationship between DRM and misinformation false memories. Memory and Cognition, 41, 832-838. 
Table 1: Demographics by Age Group

Table 1

Demographics by Age Group

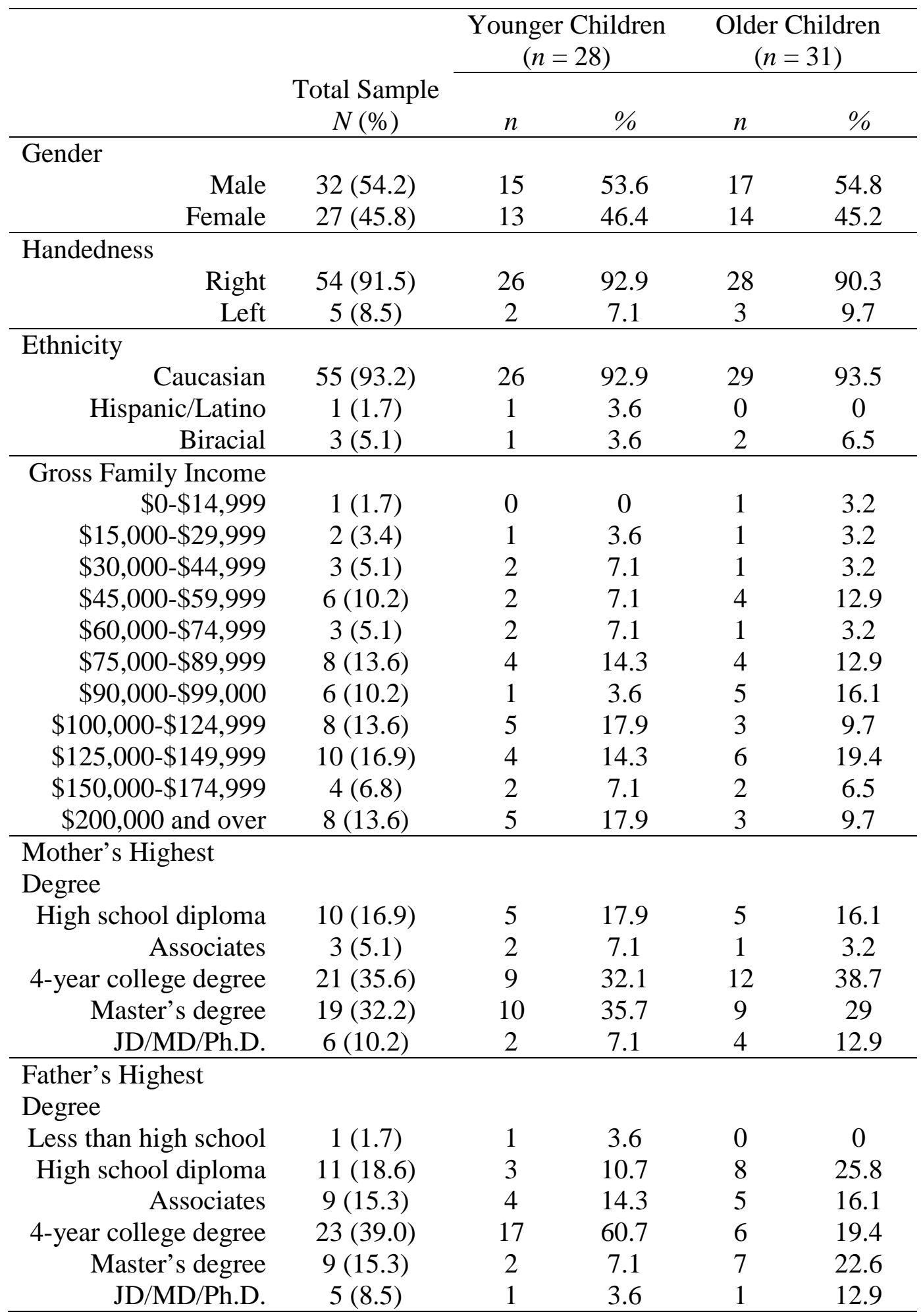


Table 2: Means and Standard Deviations of Research Tasks

Table 2

\begin{tabular}{|c|c|c|c|c|c|}
\hline \multicolumn{6}{|c|}{ Means and Standard Deviations of Research Tasks } \\
\hline & \multirow[b]{2}{*}{$\begin{array}{c}\text { Total Sample } \\
M(S D) \\
\end{array}$} & \multicolumn{2}{|c|}{$\begin{array}{l}\text { Younger } \\
\text { Children } \\
(n=28)\end{array}$} & \multicolumn{2}{|c|}{$\begin{array}{l}\text { Older Children } \\
\quad(n=31)\end{array}$} \\
\hline & & $M$ & $S D$ & $M$ & $S D$ \\
\hline \multicolumn{6}{|l|}{ WASI-II ${ }^{1,2}$} \\
\hline Vocabulary & $57.98(8.57)$ & 57.50 & 9.18 & 58.42 & 8.12 \\
\hline Matrix Reasoning & $52.27(8.61)$ & 51.50 & 8.38 & 52.97 & 8.89 \\
\hline Full-Scale IQ & $108.80(12.16)$ & 107.71 & 13.29 & 109.77 & 11.18 \\
\hline $\begin{array}{l}\text { Executive } \\
\text { Functioning } \\
\text { NEPSY-II }^{1}\end{array}$ & & & & & \\
\hline $\begin{array}{l}\text { Animal Sorting: } \\
\text { Scaled Score }\end{array}$ & 11.37 (3.60) & 11.82 & 4.32 & 10.97 & 2.81 \\
\hline $\begin{array}{r}\text { Animal Sorting: } \\
\text { Number of Sorts } \\
\text { Scaled Score }\end{array}$ & $11.56(3.42)$ & 11.89 & 4.10 & 11.26 & 2.71 \\
\hline $\begin{array}{r}\text { Inhibition: Naming } \\
\text { Combined Scaled } \\
\text { Score }\end{array}$ & $10.22(3.33)$ & 11.07 & 3.51 & 9.45 & 3.02 \\
\hline $\begin{array}{r}\text { Inhibition: Inhibition } \\
\text { Combined Scaled } \\
\text { Score }\end{array}$ & $10.34(3.04)$ & 10.36 & 2.68 & 10.32 & 3.37 \\
\hline $\begin{array}{r}\text { Inhibition: Switching } \\
\text { Combined Scaled } \\
\text { Score }\end{array}$ & $10.66(2.73)$ & 10.79 & 2.86 & 10.55 & 2.64 \\
\hline \multicolumn{6}{|l|}{ WISC-IV ${ }^{1}$} \\
\hline $\begin{array}{r}\text { Digit Span: } \\
\text { Backward Scaled } \\
\text { Score } \\
\end{array}$ & $10.10(2.48)$ & 10.5 & 2.32 & 9.74 & 2.61 \\
\hline \multicolumn{6}{|l|}{ DRM Lists } \\
\hline Recall & 35.39 (5.18) & 32.54 & 4.80 & 37.97 & 4.09 \\
\hline $\begin{array}{r}\text { Recognition }{ }^{3} \text { : True } \\
\text { Positive }\end{array}$ & $17.32(2.90)$ & 16.50 & 3.34 & 18.06 & 2.24 \\
\hline $\begin{array}{r}\text { Recognition }^{3} \text { : True } \\
\text { Negative }\end{array}$ & 77.39 (6.77) & 77.43 & 5.43 & 77.35 & 7.88 \\
\hline $\begin{array}{r}\text { Recognition }^{3} \text { : False } \\
\text { Positive }\end{array}$ & 9.61 (6.77) & 9.57 & 5.43 & 9.65 & 7.88 \\
\hline $\begin{array}{r}\text { Recognition }^{3} \text { : False } \\
\text { Negative }\end{array}$ & $3.68(2.90)$ & 4.5 & 3.34 & 2.94 & 2.24 \\
\hline COWAT: Animals & $17.76(5.34)$ & 15.5 & 5.33 & 20.30 & 4.14 \\
\hline
\end{tabular}

Note 1: WASI-II, NEPSY-II, and WISC-IV $M=10, S D=3$; Note 2: FSIQ $M=100, S D=15$;

Note 2: Previously presented words: 21; Unpresented words: 87 


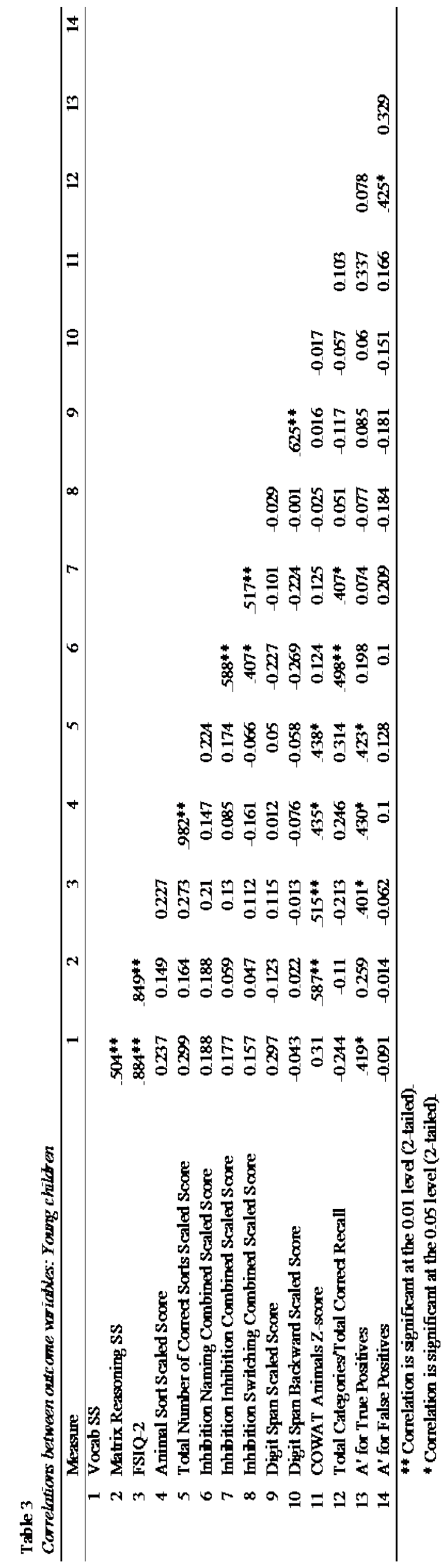




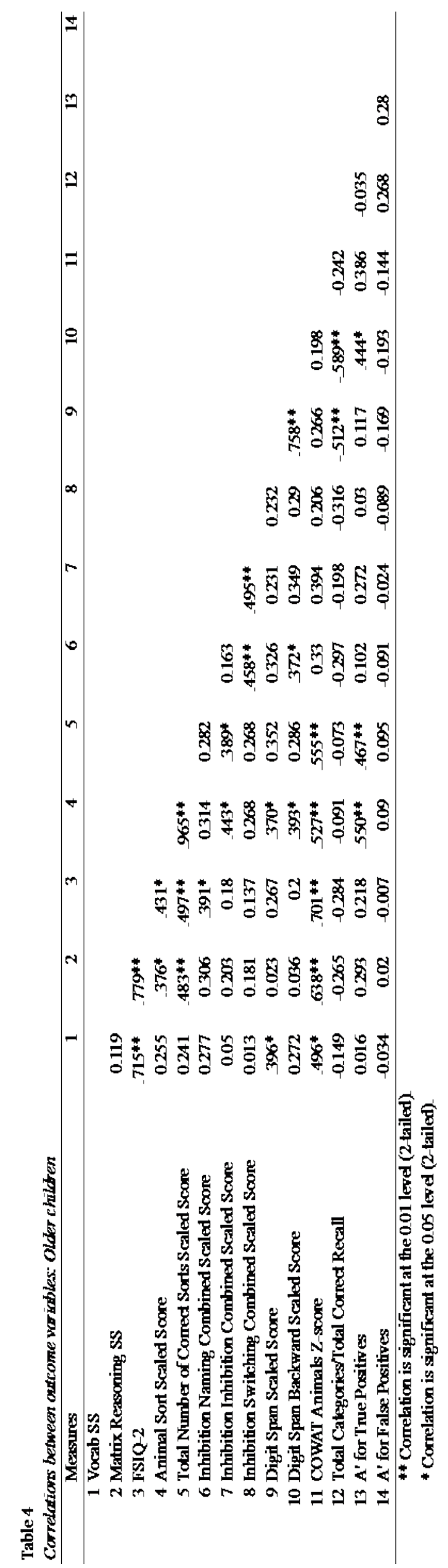


Table 5: Summary of Multiple Regression: Proportion of Critical Lure Production at

Table 5

Recall

Summary of Multiple Regression Analysis for Proportion of Critical Lure Production at Recall $(N=59)$

\begin{tabular}{|c|c|c|c|c|c|}
\hline Variable & $\mathrm{B}$ & SE(B) & $\beta$ & $t$ & Sig. $(p)$ \\
\hline \multicolumn{6}{|l|}{ WASI-II } \\
\hline Vocabulary Scaled Score & .037 & .014 & 8.914 & 2.572 & .016 \\
\hline $\begin{array}{r}\text { Matrix Reasoning Scaled } \\
\text { Score }\end{array}$ & .037 & .014 & 8.668 & 2.543 & .017 \\
\hline FSIQ-2 & -.044 & .016 & -15.277 & -2.662 & .013 \\
\hline \multicolumn{6}{|l|}{ NEPSY-II: Animal Sorting } \\
\hline Scaled Score & -.012 & .007 & -1.353 & -1.838 & .077 \\
\hline $\begin{array}{r}\text { Total Number of Sorts } \\
\text { Scaled Score }\end{array}$ & .015 & .007 & 1.619 & 2.158 & .040 \\
\hline \multicolumn{6}{|l|}{ NEPSY-II: Inhibition } \\
\hline Total Errors Scaled Score & -.002 & .008 & -.166 & -.275 & .786 \\
\hline \multicolumn{6}{|l|}{ Naming Combined Scaled } \\
\hline Score & .002 & .003 & .176 & .651 & .520 \\
\hline \multicolumn{6}{|l|}{ Inhibition Combined Scaled } \\
\hline Score & .006 & .005 & .542 & 1.232 & .229 \\
\hline $\begin{array}{r}\text { Switching Combined Scaled } \\
\text { Score }\end{array}$ & -.008 & .006 & -.569 & -1.354 & .187 \\
\hline \multicolumn{6}{|l|}{ WISC-IV: Digit Span } \\
\hline Scaled Score & -.008 & .011 & -.611 & -.723 & .476 \\
\hline Forward Scaled Score & .001 & .007 & .043 & .073 & .942 \\
\hline Backward Scaled Score & .005 & .006 & .334 & .716 & .480 \\
\hline Age & -.012 & .012 & -.169 & -.955 & .348 \\
\hline Gross Family Income & -.001 & .002 & -.051 & -.273 & .787 \\
\hline Maternal Highest Degree & .016 & .006 & .549 & 2.683 & .012 \\
\hline Paternal Highest Degree & -.004 & .006 & -.130 & -.641 & .527 \\
\hline COWAT: Animals Z-score & .003 & .004 & .146 & .811 & .424 \\
\hline
\end{tabular}

Note: FSIQ-2 = Full Scale IQ, 2 subtest 
Figure 1: Recall Mediation

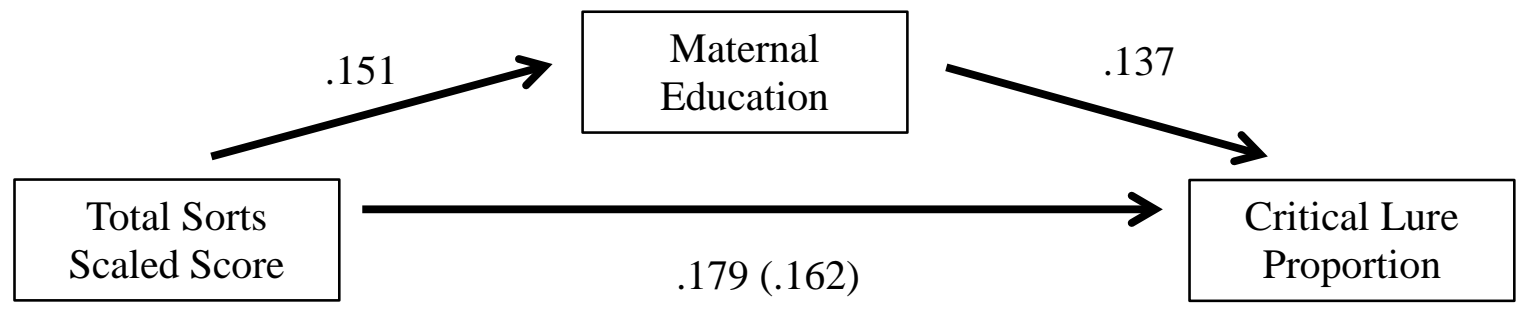

Figure 1 
Table 6

Table 6: Summary of Multiple Regression: Critical Lures at Recognition

Summary of Multiple Regression Analysis for Critical Lures Remembered at Recognition $(N=59)$

\begin{tabular}{|c|c|c|c|c|c|}
\hline Variable & B & SE(B) & $\beta$ & $t$ & Sig. $(p)$ \\
\hline \multicolumn{6}{|l|}{ WASI-II } \\
\hline Vocabulary Scaled Score & .253 & .585 & 1.895 & .433 & .669 \\
\hline \multicolumn{6}{|l|}{ Matrix Reasoning Scaled } \\
\hline Score & .199 & .587 & 1.459 & .339 & .737 \\
\hline FSIQ-2 & -.283 & .670 & -3.067 & -.423 & .676 \\
\hline \multicolumn{6}{|l|}{ NEPSY-II: Animal Sorting } \\
\hline Scaled Score & -.394 & .269 & -1.364 & -1.467 & .154 \\
\hline $\begin{array}{r}\text { Total Number of Sorts } \\
\text { Scaled Score }\end{array}$ & .422 & .288 & 1.390 & 1.466 & .154 \\
\hline \multicolumn{6}{|l|}{ NEPSY-II: Inhibition } \\
\hline Total Errors Scaled Score & .161 & .332 & .370 & .486 & .631 \\
\hline \multicolumn{6}{|l|}{ Naming Combined Scaled } \\
\hline Score & -.067 & .115 & -.200 & -.585 & .563 \\
\hline \multicolumn{6}{|l|}{ Inhibition Combined Scaled } \\
\hline Score & .073 & .205 & .199 & .358 & .723 \\
\hline $\begin{array}{r}\text { Switching Combined Scaled } \\
\text { Score }\end{array}$ & -.362 & .234 & -.824 & -1.551 & .133 \\
\hline \multicolumn{6}{|l|}{ WISC-IV: Digit Span } \\
\hline Scaled Score & -.110 & .463 & -.253 & -.237 & .814 \\
\hline Forward Scaled Score & -.083 & .298 & -.207 & -.277 & .784 \\
\hline Backward Scaled Score & .084 & .259 & .191 & .323 & .749 \\
\hline Age & -.835 & .498 & -.374 & -1.675 & .106 \\
\hline Gross Family Income & -.030 & .093 & -.076 & -.319 & .752 \\
\hline Maternal Highest Degree & .105 & .240 & .113 & .436 & .667 \\
\hline Paternal Highest Degree & .058 & .245 & .060 & .235 & .816 \\
\hline COWAT: Animals Z-score & .140 & .164 & .194 & .856 & .400 \\
\hline
\end{tabular}


Table 7

Table 7: Summary of Multiple Regression: Correct Hits at Recognition

Summary of Multiple Regression Analysis for Correct Hits at Recognition $(N=59)$

\begin{tabular}{|c|c|c|c|c|c|}
\hline Variable & $\mathrm{B}$ & SE(B) & $\beta$ & $t$ & Sig. $(p)$ \\
\hline \multicolumn{6}{|l|}{ WASI-II } \\
\hline Vocabulary Scaled Score & .035 & .054 & 2.267 & .647 & .523 \\
\hline \multicolumn{6}{|l|}{ Matrix Reasoning Scaled } \\
\hline Score & .026 & .054 & 1.679 & .487 & .630 \\
\hline FSIQ-2 & -.034 & .061 & -3.201 & -.551 & .586 \\
\hline \multicolumn{6}{|l|}{ NEPSY-II: Animal Sorting } \\
\hline Scaled Score & -.005 & .025 & -.163 & -.219 & .828 \\
\hline $\begin{array}{r}\text { Total Number of Sorts } \\
\text { Scaled Score }\end{array}$ & .023 & .026 & .658 & .867 & .394 \\
\hline \multicolumn{6}{|l|}{ NEPSY-II: Inhibition } \\
\hline Total Errors Scaled Score & -.001 & .030 & -.027 & -.044 & .965 \\
\hline \multicolumn{6}{|l|}{ Naming Combined Scaled } \\
\hline Score & .005 & .011 & .137 & .500 & .621 \\
\hline \multicolumn{6}{|l|}{ Inhibition Combined Scaled } \\
\hline Score & .010 & .019 & .246 & .552 & .585 \\
\hline $\begin{array}{r}\text { Switching Combined Scaled } \\
\text { Score }\end{array}$ & -.019 & .021 & -.368 & -.866 & .394 \\
\hline \multicolumn{6}{|l|}{ WISC-IV: Digit Span } \\
\hline Scaled Score & .004 & .042 & .076 & .089 & .930 \\
\hline Forward Scaled Score & -.010 & .027 & -.221 & -.370 & .714 \\
\hline Backward Scaled Score & .011 & .024 & .218 & .462 & .648 \\
\hline Age & .106 & .046 & .414 & 2.316 & .028 \\
\hline Gross Family Income & -.026 & .009 & -.571 & -3.011 & .006 \\
\hline Maternal Highest Degree & .029 & .022 & .273 & 1.319 & .198 \\
\hline Paternal Highest Degree & .001 & .022 & .013 & .062 & .951 \\
\hline COWAT: Animals Z-score & .025 & .015 & .302 & 1.663 & .108 \\
\hline
\end{tabular}


Table 8: Summary of Multiple Regression: False Alarms (Memories) at Recognition

Table 8

Summary of Multiple Regression Analysis for False Alarms at Recognition $(N=59)$

\begin{tabular}{|c|c|c|c|c|c|}
\hline Variable & $\mathrm{B}$ & SE(B) & $\beta$ & $t$ & Sig. $(p)$ \\
\hline \multicolumn{6}{|l|}{ WASI-II } \\
\hline Vocabulary Scaled Score & .023 & .042 & 2.588 & .548 & .588 \\
\hline \multicolumn{6}{|l|}{ Matrix Reasoning Scaled } \\
\hline Score & .022 & .042 & 2.366 & .510 & .614 \\
\hline FSIQ-2 & -.027 & .048 & -4.374 & -.560 & .580 \\
\hline \multicolumn{6}{|l|}{ NEPSY-II: Animal Sorting } \\
\hline Scaled Score & -.029 & .019 & -1.507 & -1.504 & .144 \\
\hline $\begin{array}{r}\text { Total Number of Sorts } \\
\text { Scaled Score } \\
\end{array}$ & .030 & .021 & 1.504 & 1.471 & .153 \\
\hline \multicolumn{6}{|l|}{ NEPSY-II: Inhibition } \\
\hline Total Errors Scaled Score & .028 & .024 & .954 & 1.161 & .256 \\
\hline \multicolumn{6}{|l|}{ Naming Combined Scaled } \\
\hline Score & -.010 & .008 & -.448 & -1.218 & .234 \\
\hline \multicolumn{6}{|l|}{ Inhibition Combined Scaled } \\
\hline Score & .003 & .015 & .105 & .176 & .862 \\
\hline $\begin{array}{r}\text { Switching Combined Scaled } \\
\text { Score }\end{array}$ & -.038 & .017 & -1.294 & -2.260 & .032 \\
\hline \multicolumn{6}{|l|}{ WISC-IV: Digit Span } \\
\hline Scaled Score & -.009 & .033 & -.311 & -.270 & .789 \\
\hline Forward Scaled Score & .000 & .021 & .006 & .008 & .994 \\
\hline Backward Scaled Score & .006 & .019 & .197 & .310 & .759 \\
\hline Age & -.006 & .036 & -.041 & -.172 & .865 \\
\hline Gross Family Income & -.006 & .007 & -.238 & -.931 & .360 \\
\hline Maternal Highest Degree & .013 & .017 & .212 & .761 & .453 \\
\hline Paternal Highest Degree & .000 & .018 & .003 & .012 & .990 \\
\hline COWAT: Animals Z-score & .015 & .012 & .312 & 1.278 & .212 \\
\hline
\end{tabular}

